\title{
Cidade-montagem e cidade-confluência: As "Berlins" de Döblin e de Benjamin
}

\section{City-assemblage and city-confluence: Döblin and Benjamin's “Berlins”}

\author{
Anna Flávia Dias Salles \\ Universidade Federal de Minas Gerais (UFMG), Belo Horizonte, Minas Gerais / Brasil \\ annaflavona@gmail.com
}

Resumo: Pretende-se, neste artigo, analisar aspectos dos distintos métodos narrativos com que os escritores Alfred Döblin e Walter Benjamin abordam a cidade de Berlim em suas obras, respectivamente, Berlin Alexanderplatz - a história de Franz Biberkopf, e Infância em Berlim por volta de 1900. Demonstra-se que ambos os autores logram rasurar a linha divisória entre espaços público e privado na cidade, reforçando a ideia de uma contiguidade indissociável entre estes nas obras em foco. Döblin pretende, com sua montagem literária de documentos, impregnar a Berlim ficcional de autenticidade, enquanto Benjamin se propõe, por meio de uma escrita fragmentária e errante, a abrir os acontecimentos singulares da vida citadina à dimensão histórica.

Palavras-chave: representações da cidade, montagem literária, memória.

Abstract: This article aims to analyze aspects of the distinct narrative methods with which writers Alfred Döblin and Walter Benjamin approach the city of Berlin in their works, respectively, Berlin Alexanderplatz - the story of Franz Biberkopf, and Berlin Childhood around 1900. It is established that both authors manage to erase the dividing line between public and private spaces in the city, reassuring the idea of an inseparable contiguity between them in the focused works. Döblin intends, with his literary assemblage of documents, to impregnate the fictional Berlin with authenticity, while Benjamin proposes, through a fragmentary and erratic writing, to open the singular events of the city life to the historical dimension.

Keywords: representations of the city, literary assemblage, memory. 


\section{A cidade épica}

A cidade de Berlim está inextricavelmente ligada ao cotidiano das personagens do romance Berlin Alexanderplatz - a história de Franz Biberkopf, de Alfred Döblin (2009), publicado em 1929, e do ensaio filosófico Infância em Berlim por volta de 1900, de Walter Benjamin (1987), escrito no exílio em Ibiza, na Espanha, em 1933, de onde o filósofo transfere-se para Paris, não regressando mais à Alemanha.

Para nos apoiar nas análises de tais obras como resultado do esforço crítico de ambos os escritores sobre a forma épica do romance, utilizaremos algumas das ideias contidas em ensaios de ambos, como "A crise do romance, sobre Alexanderplatz, de Döblin" (BENJAMIN, 1994), uma resenha crítica produzida ainda no calor do lançamento da obra; e "O romance histórico e nós" (DÖBLIN, 2017), em que o autor discute sobre o papel do romancista épico frente ao romance histórico, desenvolvendo formulações importantes para nossos propósitos como os conceitos de "autenticidade" e de "ressonância".

A Berlim do romance de Döblin é uma composição que se utiliza de materiais extraliterários para proceder a uma espécie de colagem textual cujo efeito aqui chamaremos de cidade- montagem, nos valendo, ainda, de algumas das questões suscitadas por Élcio Loureiro Cornelsen no artigo "Berlin Alexanderplatz, da cidade-palavra à cidade-imagem" (2004). Com a Sabrina Sedlmayer de "Sobre os restos: Infância berlinense por volta de 1900" (2011) visitaremos a casa de Benjamin buscando nos deter nos espaços em que vida privada e vida pública se confluem. Cidadeconfluência, a Berlim de Benjamin infiltra-se na vida cotidiana abrindo-a à experiência compartilhada e histórica ecoada por tempos diversos.

Contemporâneos, os dois pensadores da vanguarda artística e literária da Alemanha se dedicaram a pensar a fatura do romance como lugar para uma nova perspectiva épica. Para

Döblin, o romance épico era um "estágio do desenvolvimento da arte de narrar" (DÖBLIN, 2017, p.161), herdada de uma tradição em que memorização e transmissão se fundamentavam na oralidade. Para Benjamin, a épica moderna está em crise e se dá em meio à impossibilidade de transmissão da experiência, em colapso após a invenção da imprensa, encontrando-se, àquela altura, em vias de se reinventar, face aos novos meios de comunicação, como instrumento de superação do capitalismo.

Döblin defende que uma das tarefas do romancista épico (lembremonos de que ele escreve em 1936) seria a de "oferecer realidade reconhecível e convincente" logrando obter verossimilhança (aproximação com a 
história) com base em elementos autênticos, pois, "queremos poder acreditar nas coisas do romance ficcional e as coisas, quando não são históricas, devem pelo menos ser possíveis" (DÖBLIN, 2017, p. 161).

Esses indicadores de autenticidade foram também objeto de menção em Benjamin, para quem o material de montagem de Berlin Alexanderplatz "está longe de ser arbitrário" e "se baseia no documento". $\mathrm{O}$ autor evoca da vanguarda artística dadaísta a prerrogativa de ter usado "a seu serviço a vida cotidiana através da montagem. Foi o primeiro [o dadaísmo] a proclamar, ainda que de forma insegura, a hegemonia exclusiva do autêntico" (BENJAMIN, 1994, p. 56).

O espaço literário döbliniano se torna, na análise de Benjamin, uma espécie de estuário da metrópole de Berlim para onde são carreados versículos da Bíblia, estatísticas, textos publicitários, clichês de serviços da prefeitura... visando a "conferir autoridade à ação épica". Participa, como elemento fulcral dessa carga de autenticidade, o linguajar da obra.

O livro é um monumento a Berlim, porque o narrador não se preocupou em cortejar a cidade, com o sentimentalismo de quem celebra a terra natal. Ele fala a partir da cidade. Berlim é seu megafone. (BENJAMIN, 1994, p.57, itálico do autor)

Tal "megafone" amplifica o dialeto berlinense como dado autóctone não meramente ilustrativo mas, constitutivo da cidade. A língua do livro não é a chamada língua culta, tampouco a linguagem oral dos antigos narradores. Seu linguajar forja-se na parte baixa da cidade, no meretrício, no beco dos desvalidos, do berlinense, enfim, que, para Benjamin, "fala como conhecedor", "degusta o que diz", e, "quando insulta, zomba ou ameaça, ele toma algum tempo para fazê-lo" (BENJAMIN, 1994, p. 57). O dialeto berlinense se apresenta intrincado à língua informativa da cidade, a língua do poder, com seus avisos, regulações, textos radiofônicos, protocolos sobre tratamento contra impotência sexual e outros inumeráveis materiais textuais utilizados por Döblin. $\mathrm{O}$ escritor e ensaísta alemão proclama que a "verdadeira glória" do romancista moderno seria a de apresentar realisticamente os fenômenos pessoais e sociais fazendo entrecruzarem-se no espaço literário as "coisas da vida privada, da vida intimamente pessoal, da vida social e dialógica, coisas do indivíduo, da relação mútua entre os sexos, do amor, do casamento, da amizade". (DÖBLIN, 2017, p. 173).

Benjamin busca identificar o "sal épico" do romance de Döblin apreciando a forma como a cidade de Berlim (em especial Alexanderplatz) é alçada à protagonista em detrimento da personagem principal, Franz 
Biberkopf: "por que o livro se chama Berlin Alexanderplatz, enquanto A história de Franz Biberkopf só aparece como subtítulo"? (BENJAMIN, 1994, p. 57) se pergunta o autor. Sobre essa questão, a filósofa brasileira Carla Milani Damião (2009) vê um jogo duplo na resenha de Benjamin que elogia a "epicidade da obra" por um lado, mas condena o que ela chama de "trajetória de petit criminel ao petit bourgeois", própria, segundo cita do autor, de um "antigo romance burguês de formação".

Agradaria a Benjamin, portanto, a parte do estilo linguístico (o uso de dialetos, provérbios e expressões coloquiais) e literário do livro (a montagem que expõe documentos do dia a dia) e não o "caráter humano" ali presente. O traço de união que possa existir está em que Alexanderplatz "rege o destino" de Biberkopf - um entre os vários desempregados que por ali transitam. O que Benjamin reprova, em suma, é a cura do personagem. (DAMIÃO, 2009, p. 54)

Benjamin entende, portanto, a suposta "cura" de Biberkopf como resultado de estratégias do Bildungsroman, o "romance de formação", quando, ao contrário, Döblin parece desejar parodiar o gênero de forma crítica. O ideário otimista de desenvolvimento moral e de redenção por meio da conversão a uma "vida decente" se apresenta na obra de forma irônica, descrente.

Alexanderplatz, o raio de no máximo mil metros em que se move a existência de Franz Biberkopf (Benjamin), cenário onde se forja o linguajar-linguagem do romance, nos é apresentada pelo crítico berlinense. Aquela área em que rugiam trens subterrâneos sofria, há dois anos, a ação violentamente transformadora de guindastes e escavadeiras que escancaravam, "mais profundamente que em qualquer outro lugar, as vísceras da grande cidade", para onde

se abrem à luz do dia os pátios dos fundos em torno da praça Georgenkirch, e onde se preservara mais silenciosamente que em outras partes da cidade, nos labirintos em torno da Marsiliusstrasse (onde as secretárias da Polícia dos Estrangeiros estão alojadas em cortiços) e em torno da Kaserstrasse (onde as prostitutas praticam, à noite, suas rondas imemoriais), remanescentes intactos da última década do século passado. Não é um bairro industrial, e sim comercial, habitado pela pequena burguesia. No meio de tudo isso, o negativo sociológico desse meio: os marginais, reforçados pelos contingentes de desempregados. Biberkopf é um deles. (BENJAMIN, 1994, p. 57-58) 


\section{A pena começa... na Berlim-montagem}

Libertado da prisão, colado ao muro vermelho da penitenciária, horrorizado por não mais pertencer ao grupo dos que lá dentro catavam batatas, ou ainda "carpintejavam, envernizavam, selecionavam, colavam" (DÖBLIN, 2009, p. 13), Franz Biberkopf não toma os primeiros bondes elétricos que passam. Instado pelo guarda do presídio, tropeça no próprio pé, toma impulso e se senta no próximo bonde que dispara. A cidade o devora num redemoinho de eventos sensoriais:

Ruas animadas surgiam, a Seestrasser, pessoas subiam e desciam. Dentro dele, o grito soava terrível: atenção, atenção, vai começar. A ponta de seu nariz gelou, sua bochecha vibrava. "Jornal vespertino do meio-dia". "B.Z." "A mais nova revista", "a Funkstunde", "subiu mais alguém?". Os policiais agora usam uniformes azuis. Desceu do vagão sem que ninguém percebesse, estava no meio das pessoas. E daí? Nada. Olhe a postura, seu porco esfomeado, controle-se, vai sentir o cheiro do meu punho no nariz. Formigueiro, que formigueiro. Como tudo se movimentava. Meu miolo parece que não tem mais banha, deve ter secado por completo. O que era tudo isso? Lojas de calçados, lojas de chapéus, lâmpadas, lojas de bebidas destiladas. As pessoas precisam de sapatos se andam tanto de um lado para o outro, nós também tínhamos uma sapataria, vamos manter isso em mente. Quebravam o calçamento da Rosenthaler Platz, caminhou entre os outros sobre pranchas de madeira. A gente se mistura aos outros, aí tudo passa, daí você não percebe nada, cara. Manequins posavam nas vitrines com ternos, casacos, saias meias e sapatos. Do lado de fora tudo se movimentava mas, lá atrás, não havia nada! Nada parecia ter vida! Tinham rostos alegres, riam, aguardavam na ilha, diante do Aschinger, em dois, ou em três, fumavam cigarros, folheavam jornais. Ficavam como os postes - e - cada vez mais imóveis. Faziam par com as casas, tudo branco, tudo madeira. (DÖBLIN, 2009, p. 14)

A cidade-vórtice que o traga cada vez mais para o fundo, "não podia voltar, viera de bonde de tão longe até aqui, fora solto da prisão e precisava entrar aqui, bem mais fundo", (DOBLIN, 2009, p. 15) presta-se bem aos influxos da metáfora do mar com que Benjamin introduz sua resenha, nos advertindo sobre as diferentes formas que com este podemos nos relacionar. Não estamos aqui diante de um poeta épico que se deita na praia para ouvir as ondas ou colher moluscos, tampouco de um narrador mercador que leva e traz histórias de além mar. Aserenidade 
marítima "fora perturbada por ondas tão altas de acontecimentos e reflexões" (BENJAMIN, 1994, p. 56) que nos encontramos chacoalhados, como Biberkopf, no bonde, em meio aos solavancos da linguagem. $\mathrm{Ou}$, na bela formulação de Benjamin, nos encontramos "molhados, até os ossos, pela espuma da linguagem verdadeiramente falada". Biberkopf encontra-se, no trecho acima citado, em meio a um amontoado de sensações auditivas, visuais, olfativas, cinéticas.

Tais efeitos não provêm de descrições minuciosas, detidas em pormenores que ofereçam, progressivamente, elementos ao trabalho imaginativo do leitor. $\mathrm{O}$ procedimento requer uma leitura de adesão avassaladora, o leitor é sugado não por imagens isoladas, mas pelo ritmo que as preside, como é próprio do efeito de montagem pretendido pelo autor, de que falaremos a seguir.

Referindo-se aos materiais de toda ordem que "enxameiam" no romance de Döblin, Benjamin, que pelo menos desde 1927 colecionava suas Passagens, reflete que, "em seus melhores momentos, o cinema tentou habituar-nos à montagem. Agora, ela se tornou, pela primeira vez, utilizável para a literatura épica"(BENJAMIN, 1994, p. 56). As vanguardas alemã e russa já haviam produzido (ou produziram concomitantemente à escrita do romance de Döblin) seus Berlim, sinfonia de uma grande cidade, de Walther Ruttmann (1927) e O homem com a câmera, de Dziga Vertov (1929), respectivamente. A montagem em ambos os filmes, ora plácida, ora acelerada em fusões e superposições, ritmos que pretendem se imiscuir das temporalidades próprias das metrópoles, inspira a observação de Benjamin.

A relação entre cidade literária e cidade cinematográfica foi objeto de análise empreendida por Elcio Loureiro Cornelsen no artigo "Berlin Alexanderplatz, da cidade-palavra à cidade- imagem" (2004), em que o autor se propõe a analisar o processo de transcriação intersemiótica na representação da cidade de Berlim transposta do romance de Döblin para a série de TV homônima dirigida pelo cineasta alemão Rainer Werner Fassbinder, lançada em 1980.

O pesquisador vê no trabalho de Döblin um procedimento artesanal de montagem de textos extraliterários, movido por "fatos' textuais" e não apenas pelo “ 'gênio' criativo do autor” que, desta forma, se torna um montador. A problemática do artigo é, principalmente, pensar as estratégias utilizadas por Fassbinder para transpor para uma peça televisiva a cidade literária. Partindo de críticas feitas na época de seu lançamento, especialmente aquelas publicadas pelo escritor e crítico literário suíço 
Hermann Burger, que se mostra ressentido pela ausência de Alexanderplatz nas imagens (o título de seu ensaio, nos informa Cornelsen, é "Sem lugar para a Alexanderplatz"), o autor contrapõe-se com base no fato de que a cidade literária não é um mero dado cênico. Para Cornelsen, a escrita döbliniana imagina uma Berlim mural, "uma Berlim que ultrapassa meramente o status de Kulisse (cenário, bastidor) [e] se materializa em sua totalidade através do jornal, da previsão do tempo, do reclame, do sucesso a tocar no rádio, do noticiário político". (CORNELSEN, 2004, p.18). Seu argumento se desenvolve no sentido de defender a autonomia criativa de Fassbinder e a forma como este projeta, mesmo nas cenas realizadas predominantemente em espaços interiores, a Alexanderplatz exterior. Para nosso intento, cabenos reter aqui o aspecto de que a Berlim döbliniana quer realizar-se como metrópole literariamente, uma vez que "o discurso literário da modernidade torna possível a simulação da atividade dos suportes sensoriais por meio da montagem e colagem de textos do cotidiano". (CORNELSEN, 2004, p. 19).

Tal efeito de montagem produz uma ambiência metropolitana que, saturada por toda gama imagética e textual, não se trama apenas em um espaço exterior à vida privada das personagens. Essa malha de acontecimentos, ou esse "emaranhado", no dizer de Cornelsen, infiltra-se mesmo na cena mais intimista posta no interior de umínfimo compartimento onde quer que se encontre Franz Biberkopf. O romance quer pontilhar a linha de privacidade e de proteção que o ambiente doméstico confere às vidas burguesas. Os discursos textuais e sígnicos em voga na cidade e o arco da vida de Biberkopf encontram-se de tal forma atados que não se pode destacar uma coisa da outra sem que se desarme o dispositivo do romance.

\section{Berlim-Confluência}

Para se analisar as vias de ventilação entre espaços citadinos e domésticos em Infância passada em Berlim por volta de 1900 (1987) é frutífero, antes, se pensar sobre a voz do "eu" do texto. Sabrina Sedlmayer (2011) situa bem as questões suscitadas pela escrita que reputa como "antiautobiográfica" de Benjamin e, em especial, nessa obra, em que identifica um escritor vigilante no sentido de conter o "eu" do enunciado na perspectiva do sujeito histórico, evitando dar espaço demasiado para a própria subjetividade. Para ela, deseja o autor "que a palavra 'eu' apenas represente o trabalho misterioso da memória, as infinitas interpolações naquilo que já se foi, e se abra para o avesso do ensimesmamento, a experiência do choque". (SEDLMAYER, 2011, p. 55). 
Refere-se a pesquisadora ao choque entre tempos, entre passado e presente, que, em sua revisitação memoriosa a Berlim, Benjamin detecta. Em suas deambulações, o autor colige locais, obras, objetos, monumentos que, atravessados por ecos de outros tempos, provocam-lhe lampejos à semelhança da sensação fugidia de um "déjà vu”, embora, para ele, a expressão francesa pareça insuficiente para designar essa experiência, como se percebe no fragmento "Notícia de uma morte":

Será tal expressão [déjà $v u$ ] realmente feliz? Não se deveria antes falar de acontecimentos que nos atingem na forma de um eco, cuja ressonância que o provocou parece ter sido emitida em um momento qualquer na escuridão da vida passada? Além disso, acontece que o choque com que um instante penetra em nossa consciência, como algo já vivido, nos atinge, o mais das vezes, na forma de um som. É uma palavra, um rumor ou um palpitar, aos quais se confere o poder de nos convocar desprevenidos ao frio jazigo do passado, de cuja abóboda o presente parece ressoar apenas como um eco. (BENJAMIN, 1987, p. 89).

Tais detecções, próprias do escritor moderno, foram também objeto de formulação em Döblin no ensaio "O romance histórico e nós" (2017), no qual examina o conceito de "ressonância" para se referir aos ecos e iluminações entre passado e presente na escrita épica.

Ele [o verdadeiro artista] carrega em si um ressoador especialmente delicado e sofisticado. E quando certas coisas históricas de que ele gosta (é preciso que ele goste delas) chegam suficientemente perto, o ressoador vibra e ele, o cientista, será um escritor ou um poeta, se souber transformar a ressonância em linguagem e imagens. (DÖBLIN, 2017, p. 178)

Dirigindo as palavras de Döblin à itinerância de Benjamin, podemos reconhecer o "ressoador" deste último deambulando, pela imaginação, por velhos lugares conhecidos de Berlim. Em sua recomposição, Benjamin buscava, diria Döblin, "abrir a boca aos mortos, movimentar seus esqueletos ressecados” (DÖBLIN, 2017, p. 179), fazendo reemergir a Berlim de sua infância e seus inseparáveis escombros.

$\mathrm{O}$ ressoador de Benjamin ou, se quisermos, seu sismógrafo, peregrina, sensível, pelos rumores da Berlim de sua infância. Retomando as reflexões de Sedlmayer, Benjamin faz seu "pensamento itinerante", expressão que a autora cita do escritor e crítico francês Maurice 
Blanchot, com um eu menos individualista e mais gregário, menos particularizado e mais social.

Essa espécie de eu vazado pela experiência se reflete em um dos trechos de Infância examinados pela autora: o fragmento "Loggias" (BENJAMIN, 1987, p. 132), vocábulo italiano mantido por Benjamin no original, que ela traduz por varandas e/ou galerias semiabertas sustentadas por colunas - no caso da experiência do filósofo, por cariátides. Sedlmayer percebe nesse espaço entreaberto uma forma de compreender o lugar sempre transitório ou o entre-lugar que caracteriza, no ver da autora, toda a obra benjaminiana.

As loggias eram o lugar da casa contíguo ao exterior, voltadas para o bairro, para a cidade, lugar onde, nos conta Benjamin, roupas eram estendidas em varais, de onde se podia ver uma árvore em crescimento em cuja cerca protetora cocheiros dependuravam suas capas para proceder ao trato dos cavalos. Era o lugar onde se batiam tapetes, onde se arejavam colchões, onde as manhãs "há muito já eram manhãs" quando alguém ali chegava. Era, ainda, o lugar da "tertúlia de leitores", onde os meninos liam Romeu e Julieta. As loggias, portanto, não eram lugar privado de um morador, de uma família, ao contrário, tratavam-se de espaços compartilhados, pontilhados, frequentados por muitos. A menção às loggias, que Benjamin faz também no fragmento "Rua Blumeshof, 12" (BENJAMIN, 1987, p. 95), como lugar que lhe "facultava a visão dos pátios das casas vizinhas com porteiros, crianças e tocadores de realejo", denota esse movimento constante de explorar, por meio de seus fragmentos, as fronteiras nas quais ocorrem experiências coletivas, históricas, e não particulares, mesmo em se tratando do cotidiano domiciliar. Berlim começa nas loggias, afirma Benjamin, o "próprio Deus da cidade" começa nelas e "sob sua guarda se reconciliam o tempo e o espaço”. (BENJAMIN, 1987, p. 134).

Essas varandas que davam para os pátios são também atravessadas por outras experiências compartilhadas. As confluências entre pobres e ricos são tema do fragmento "Um anjo de natal" (BENJAMIN, 1987, p.120). No pátio contíguo às loggias o menino Benjamin via aproximaremse as crianças pobres vendendo ovelhinhas de lã, as quais, juntamente com outros meninos ricos, comprava por ordens paternas, forma que os adultos encontraram para abrandar os constrangimentos que cercavam as relações entre os que davam e recebiam esmolas. $\mathrm{Na}$ varanda, à vista de todos, estava a árvore natalina enfeitada pela mãe, a despeito da família ser de origem judaica. Em seu quarto, aguardando 
soarem as seis horas, o menino Benjamin se deixa trespassar por "uma flecha que vibra no coração do dia":

Já estava escuro; apesar disso não acendi a lâmpada para não desviar o olhar das janelas que davam para o pátio, atrás das quais se viam agora as primeiras velas. De todos os momentos da existência da árvore de Natal aquele era o de maior ansiedade, momento em que sacrifica à escuridão agulhas e ramos para não ser nada além de uma constelação inacessível e, no entanto, bem próxima, atrás da janela embaçada de uma moradia dos fundos. Porém, como aquela constelação por vezes agraciava uma das janelas abandonadas, enquanto muitas permaneciam escuras, e outras, ainda mais tristonhas, se atrofiavam à luz de gás da noite emergente, parecia-me que essas janelas natalinas continham em si a solidão, a velhice e a indigência - tudo aquilo que os pobres calam. (BENJAMIN, 1987, p. 121).

Transmutada pelo olhar da criança em uma constelação, a árvore natalina ilumina, desperta e conecta as janelas do entorno antes isoladas ou apagadas. Entre janelas e loggias, a experiência de Benjamin palmilha passagens, corredores, estruturas basculantes que se abrem entre classes sociais distintas.

No fragmento "O telefone" (BENJAMIN, 1987, p.79) somos apresentados ao aparelho que já era um "consolo para a solidão" de uma geração mais jovem quando, adulto, o escritor o convoca de lá do "corredor escuro" onde habitava. O objeto aparece como um "herói lendário", um viajante do tempo, indo e vindo da maturidade, à infância e à juventude de Benjamin. O mesmo aparelho que "ganhou os aposentos iluminados" habitados por gerações mais jovens e "que piscava com a luz da derradeira esperança" para os desesperados, perturbara outrora não apenas as tardes de sesta de seus pais como também "a época da história universal no curso da qual adormeceram” (BENJAMIN, 1987, p.80).

Instalado, conforme indica o autor, "entre o baú de roupa suja e o medidor de gás", o aparelho fissura o espaço privado e ganha as redondezas ao despertar, com seu som potente, a atenção sobressaltada dos vizinhos. É possível imaginar uma cadeia deles interrompendo tarefas rotineiras e especulando sobre que voz desejava ali se enunciar pela campainha, até que, apressado, o jovem Benjamin finalmente continha o som estridente da engenhoca "arrancando- lhe os dois auscultadores que tinham peso de halteres" (BENJAMIN, 1987, p.80). Torna-se difícil resistir a discorrer benjaminianamente sobre o aparelho que se tornaria familiar a tantos de 
nós num futuro próximo, cada vez menor e mais apresentável, tomando seu lugar na mobília de salas e copas onde encontrava-se disponível também para vizinhos ainda resistentes a adquirir os próprios, e que, numa trajetória cada vez mais vertiginosa em direção à sua miniaturização como aparelho multifuncional pessoal, ganharia bolsos e cabeceiras, onde guardaria, privatizadas, inclusive nossas redes de relações.

\section{Considerações finais}

Chamamos a atenção para alguns aspectos que marcam as distintas temporalidades da escrita das duas obras bem como das diferentes espacialidades nelas abordadas. Berlin Alexanderplatz é um romance "aqui-e-agora", escrito no período de 1927 a 1929, publicado neste último. A própria resenha de Benjamin sobre a obra de Döblin, também escrita "a quente" (em 1930), nos informa sobre a perturbação que esta causara na "serenidade do leitor", registrando "a perplexidade de muitos leitores desse novo livro" (BENJAMIN, 1994, p. 56). Para dar conta, no estilo, da cacofonia de Alexanderplatz, lugar dos párias, da violência e da pobreza, Döblin faz sua composição heterogênea de elementos nas quais o protagonista do romance, Franz Biberkopf, é tragado. A cidade do lumpen com seu cotidiano febril e violento, parece infiltrar-se em seus pensamentos e reger seus desígnios.

Infância é uma incursão memoriosa de um Benjamin que viveu na região nobre de Berlim, em Grunewald e Charlottengurg. Escrita após pelo menos três décadas da data em que, no título, menciona corresponder à sua infância (por volta de 1900) quando o autor já encontrava-se num exílio que não teria mais fim, é um texto fragmentário, cravejado de imbricações temporais diversas. A personagem que, vestida de primeira pessoa, perambula em diferentes idades pela casa da infância de Benjamin margeia o precipício, inscrevendo o tenebroso momento presente da guerra numa perspectiva histórica.

Em ambos os autores a cidade é viva, caleidoscópica, é ruína e projeta-se adiante.

\section{Referências}

BENJAMIN, Walter. A crise do romance (1930). In: ___. Magia e técnica, arte e política: ensaios sobre literatura e história da cultura. Obras escolhidas: I. 7. ed. São Paulo: Brasiliense, 1994. p. 54-60. 
BENJAMIN, Walter. Sobre o conceito de história. In: . Magia e técnica, arte e política: ensaios sobre literatura e história da cultura. Obras escolhidas: I. 7. ed. São Paulo: Brasiliense, 1994. p. 222-232.

BENJAMIN, Walter. Infância em Berlim por volta de 1900. In: Rua de mão única. Obras Escolhidas II. Trad. Rubens Rodrigues Torres Filho e José Carlos Martins Barbosa, São Paulo: Brasiliense, 1987.

CORNELSEN, Elcio Loureiro. Berlin Alexanderplatz - da cidade-palavra à cidade-imagem. Devires, Belo Horizonte, v. 1, n. 2, p. 8-31, 2004. Disponível em: $<$ http://www.fafich.ufmg.br/devires/index.php/Devires/ article/view/231>. Acesso em: 08 jun. 2018.

DAMIÃO, Carla Milani. A resenha "Crise do romance" de Walter Benjamin: Alfred Döblin e Berlin Alexanderplatz. Artefilosofia, Ouro Preto, v. 6, p. 44-56, abr. 2009. Disponível em: <www.periodicos.ufop. br/pp/index.php/raf/article/download/694/650>. Acesso em: 8 jun.2018.

DÖBLIN, Alfred. Berlin Alexanderplatz. Tradução de Irene Aron. São Paulo: Martins Fontes, 2009. p. 9-47.

DÖBLIN, Alfred. O romance histórico e nós (1936). In: . A construção da obra épica e outros ensaios. Trad. Celeste Ribeiro de Sousa e Alceu João Gregory. Florianópolis: EDUFSC, 2017. p. 159-186.

GAGNEBIN, Jeanne Marie. Da escrita filosófica em Walter Benjamin. In: SELIGMANN-SILVA, Márcio (Org.). Leituras de Walter Benjamin. São Paulo: Fapesp; Annablume, 1999.

SEDLMAYER, Sabrina. Sobre os restos: 'Infância berlinense por volta de 1900'. Cadernos Benjaminianos, Belo Horizonte, n. 4, p. 51-59, ago.dez. 2011. Disponível em: <http://www.periodicos.letras.ufmg.br/index. $\mathrm{php} /$ cadernosbenjaminianos/article/vie w/5336/4744> . Acesso em: 8 jun.2018.

Recebido em: 8 de outubro de 2018 Aprovado em: 22 de novembro de 2018 